\title{
QT Interval Prolongation Among Patients with Chronic Liver Disease Attending Jimma Medical Center Gastroenterology Clinic, Southwest Ethiopia
}

\author{
Tadelle Amanuel, Banjaw Zelalem (i) \\ Department of Biomedical Sciences, Jimma University, Jimma City, Ethiopia \\ Correspondence: Tadelle Amanuel, Email newaman09@yahoo.com; amanuel.muluneh@ju.edu.et
}

\begin{abstract}
Background: Liver disease affects the electrophysiology of the heart. ECG abnormalities, especially QT interval prolongation are common in CLD. Heart rate affects QT interval, so QT interval is reported as corrected QT interval (QTc). The mechanism of QTc interval prolongation in patients with CLD is related to dysfunction of the autonomic nervous system.

Objective: To assess QT interval prolongation among patients with chronic liver disease.

Methods: The semi-structured questionnaire, ECG machine, automatic serum analyzer, and centrifuge were data collection instruments. Serum HDL, total proteins, albumin, bilirubin, electrolytes, triglycerides, total cholesterol, and fasting glucose were measured during data collection. LDL cholesterol was calculated. Prothrombin time was measured and INR was calculated. The severity of liver diseases was determined by the child Pugh classification (CTP score), so patients were classified by CTP score (class A, class B, or class C).
\end{abstract}

Results: Twenty-seven (32.5\%) were males and 56 (67.5\%) were females. Thirty-nine (47\%) patients were in child class B and 44 (53\%) patients were in child class C. However, no patients were in child class A. Among all male CLD patients, 14 (35.9\%) were in child class B and 13 (29.5\%) were in child class C. Among all female patients, 25 (64.1\%) were in child class B and 31 (70.5\%) were in child class C. $52(94.5 \%)$ of the patients had QT prolongation, $49(89.1 \%)$ of the patients had QTc prolongation. Among QT prolongation, 24 (61.5\%) was in Child B, 28 (63.6\%) was in Child C, and among QTc prolongation, 6 (15.4\%) was in Child B, 43 (97.7\%) was in Child C. The independent factors significantly associated with QT interval prolongation in this study were systolic hypotension $(\mathrm{p}=0.003)$ and overweight $(\mathrm{p}=0.018)$.

Conclusion: QT and QTc prolongation was observed. The prolongation also was increased especially when the disease is more advanced like in child $\mathrm{C}$.

Keywords: CLD, Q-T interval, child-Pugh classification

\section{Introduction}

Chronic liver disease (CLD) is disordered liver function lasting for at least six months. ${ }^{1}$ The heart and the liver are related intimately. Thus, patients with heart failure cause liver disease. Contrarily, CLD affects the electrophysiology of the heart. ECG abnormalities, especially QT interval prolongation are common in CLD. ${ }^{2}$ Heart rate affects QT interval, so QT interval is reported as corrected QT interval (QTc). ${ }^{3}$

QT interval shows the time interval between depolarization and repolarization of ventricular cardiomyocytes. Increased action potential duration of ventricular myocardial cells causes QT interval prolongation. QT interval prolongation is primarily based on ion channel current reduction in plasma membranes of cardiomyocytes which in turn causes long period repolarization. ${ }^{4}$ The mechanism of QTc interval prolongation in patients with liver disease is related to dysfunction of the autonomic nervous system, ${ }^{5}$ and sometimes cytokines, endotoxins, and bile salts, due to 
Porto-systemic shunts. ${ }^{6}$ Decreased function of potassium channels in ventricular myocytes also causes QT interval prolongation. ${ }^{4}$ But it is assumed as follows. Patients with liver cirrhosis cause autonomic cardiovascular dysfunction. ${ }^{7-10}$ The electrical stability of the heart is determined by the baroreceptor reflex. ${ }^{11-15}$ Patients with liver cirrhosis exhibit intense systemic activity and hyperdynamic circulation. This intern brings about a high cardiovascular output (CO) and decreased vascular resistance. These cause myocardial redesigning and left ventricular hypertrophy (LVH), which causes systolic and diastolic dysfunction and cirrhotic cardiomyopathy. ${ }^{12-14}$ Cirrhotic cardiomyopathy is a cardiac dysfunction characterized by the loss of stress-related contractile reaction accompanied by electrophysiological changes in the absence of known cardiac diseases. ${ }^{15}$ Patients with advanced cirrhosis (child class B, child class C) usually have rhythm disturbances (tachycardia, bradycardia). Inability to maintain increased heart rate may later contribute to reduced cardiac output, insufficient to meet the needs of systemic circulation. ${ }^{16,17}$

\section{Materials and Methods}

Ethical clearance was obtained from the IRB of Jimma University Health Institute. Then, a recommendation letter was written to Jimma Medical Center gastroenterology clinic head office from the department of biomedical sciences. Informed consent was obtained from study participants. To preserve confidentiality, the recorded data was not being accessed by a third person except the principal investigator. Generally, confidentiality was kept. All adult patients with liver disease attending Jimma Medical Center gastroenterology clinic were the source population. However, selected chronic liver patients who were on follow-up, patients who were above 18 years old, generally patients fullfilling the inclusion criteria were the study population. But Liver disease patients with a duration lower than 6 months, patients having incomplete medical records during data collection, patients taking medications that affect ECG, patients with previous cardiac-related diseases (ischemic heart disease, infection of cardiomyocytes, coronary revascularization, CHF), patients with an implanted cardiac pacemaker, patients with (CKD), pulmonary-related disease, thyroid disease, pregnant women and patients taking warfarin were excluded in the study. After checking inclusion and exclusion criteria, 83 CLD patients above 18 years old and those diagnosed and confirmed by a laboratory, physical examination, and ultrasound were included in the study. The presence of CLD was confirmed by physical, clinical, biochemical, and ultrasound examination. Child-Pugh classification (child class A, child class B, child class C) was used to classify disease severity. Data about sociodemographic and anthropometric measurements were collected.

\section{Data Collection Equipment}

A semi-structured questionnaire about the patient's socio-demography, ECG machine, blood centrifuge, sterile syringe, BP cuff, stadiometer, antiseptics, surgical blade, digital balance, and Human Star Model 80 analyzer was used for data collection.

\section{Data Collection Procedure}

Eighty-three Chronic liver patients confirmed by physical examination, biochemical, and ultrasound were selected among all GIT patients. Two BSc nurses trained in ECG measuring and sample collection, laboratory technicians for serum analysis, and cardiologists for blind ECG interpretation were included to conduct the study. Personal protective equipment (glove, gown, and eye goggle) was given to data collectors to protect cross-contamination during taking a blood sample and measuring ECG. Leads were cleaned with antiseptic (povidone-iodine) for every round of ECG measurement. Communication with the patient was held and permission was received from patients to conduct the procedure. The patient's hairy chest on which leads are applied was shaved by per individual surgical bled. The patient's chest was cleaned with antiseptics especially by povidone-iodine. Gel and leads were applied, and ECG was measured, and the findings were printed. The etiologies of CLD (alcohol abuse, hepatitis virus infection, autoimmune disease, medication, NAFLD) and complications of CLD (ascites and hepatic encephalopathy) were recorded from the assessment sheet of the patients. Serum HDL, total proteins, albumin, bilirubin, electrolytes, triglycerides, total cholesterol, and fasting glucose were measured during data collection. LDL cholesterol was calculated as LDL-chol = total chol - HDLchol- TG/5, where TG/5 is an estimate of VLDL cholesterol, and all values were expressed in $\mathrm{mg} / \mathrm{dl}$. Prothrombin time was measured and INR was calculated. 
It was calculated as INR $=(\mathrm{PT} \text { patient/MNPT })^{\mathrm{ISI}}$

where INR is an international normalized ratio,

MNPT is mean normal prothrombin time,

ISI is the international sensitivity index.

Blood pressure was measured. The severity of liver diseases was determined by the child Pugh classification (CTP score), so patients were classified by CTP score (class A, class B, and class C). ${ }^{18}$

\section{Blood Pressure Measurements}

Blood pressure was measured using an aneroid sphygmomanometer. The measurement protocol is as follows. After a supine rest of five minutes, two measurements in the sitting position at 5 minutes interval on the left and right hand were done. The mean of both the two measurements was used as the systolic and diastolic blood pressures.

\section{Blood Sample Collection and Analysis}

Five $\mathrm{mL}$ of venous blood was drawn from each CLD patient using a disposable plastic sterile syringe. The blood was poured into a serum separator tube (SST) before clot formation and then centrifuge. Because serum was kept for a longer period ( $>4$ weeks), it was maintained at negative $80^{\circ} \mathrm{C}$ in the refrigerator till biochemical analysis was carried out. serum $\mathrm{HDL}$, total protein, albumin, bilirubin, triglyceride, electrolytes $(\mathrm{K}, \mathrm{Na}, \mathrm{Cl}$, ionized, and total $\mathrm{Ca}$ ions), glucose, $\mathrm{PH}$, and total cholesterol were measured with a spectrophotometer using a human star model 80 analyzer during the study. All laboratory results within the reference range were used.

Blood glucose analysis was done to measure the amount of glucose in the blood. In this study, fasting blood sugar was determined using a human star 80 -analyzer machine from serum. ${ }^{19}$

\section{Electrocardiogram Measurements}

The standard 12 lead ECG tracing was recorded using the paper speed of $25 \mathrm{~mm} / \mathrm{s}$ at $10 \mathrm{mv}$ amplitude for each patient. The cardiologist interpreted all 12 lead ECG tracings blindly. The cardiologist was blind to the medical history of the patients. Maximum QRS voltage in the standard 12-lead electrocardiograph as well P, PR, QRS, R-R, and QT interval was measured. Other ECG parameter abnormalities like arrhythmias, ventricular hypertrophy, atrial enlargement, axis deviation, and conduction blocks were assessed. In leads, the QT interval is always measured from the beginning of the QRS complex to the endpoint of the T wave. To record the average of ECG parameters, 3 consecutive heart beats in the lead are needed. T wave is terminated when it is returned to the isoelectric line. QT interval was corrected using the standard correction Bazett's formula: $\mathrm{QT} / \sqrt{\mathrm{RR}} / \mathrm{S}$ ) since it is affected by heart rate. Since modern electrocardiograph record QTc interval automatically, calculated QTc was compared with an automatic record of QTc by an electrocardiograph. When QTc is greater than $440 \mathrm{~ms}$ for males and $460 \mathrm{~ms}$ for females, it is said QT is prolonged. ECG is said to be abnormal if one of the parameters is abnormal according to Minnesota code classification. ECG Minnesota code was used to classify ECG parameter abnormalities.

Electrocardiograph model no YSIPL-155 was used. Either the power cord was connected to the wall outlet during data collection or charged before to make it ready. Patients were prepared according to the clinical protocol. Limb Sensor was placed on the smooth fleshy area of upper arms and lower legs.

Six Chest leads were placed on the study subjects as follows:

V1: on fourth intercostal space at the right border of the sternum.

V2: on fourth intercostal space at the left border of the sternum.

V3: on the midway between position V2 and position V4.

V4: at the left mid-clavicular line in the fifth intercostal space.

V5: at the anterior axillary line on the same horizontal level as v4.

V6: at the mid-axillary line on the same horizontal level as v4 and v5. ${ }^{20}$ 


\section{Statistical Analysis}

Data were cleaned and edited before analysis. Data were entered into Epi data version 3.1 and were exported to SPSS version 21 for analysis. Continuous variables were reported as the mean and standard deviation. Categorical variables were reported as frequencies and percentages. Categorical variables were compared between groups with a chi-square test. Pearson's correlation coefficient was used to show the association. Binary logistic regression was used to assess the correlation between variables.

\section{Results}

Eighty-three CLD patients were included in the study. The response rate was $100 \%$. Twenty-seven (32.5\%) were males and $56(67.5 \%)$ were females. The mean age of the patients was $42.4 \pm 13$. Fourteen (16.9\%) took alcohol. Four (4.8\%) were smokers. Thirty-three (39.8\%) were khat chewers. Thirty-nine (47\%) patients were in child class B and $44(53 \%)$ patients were in child class C. But no patients were in child class A. Among all male CLD patients, 14 (35.9\%) were in child class B and 13 (29.5\%) were in child class C. Among all female patients, 25 (64.1\%) were in child class B and 31 (70.5\%) were in child class C (Table 1). The etiologies of liver disease were hepatitis B virus 34 (41\%), hepatitis $C$ virus

Table I Sociodemographic Characteristics of Chronic Liver Patients

\begin{tabular}{|l|l|}
\hline Variables & Mean and Standard Deviation (Frequency) \\
\hline Age (year) & $42.4 \pm 13$ \\
\hline Sex (men/women) $(\mathrm{n})$ & $27(32.5 \%) / 56(67.5 \%)$ \\
\hline Alcohol intake & $14(16.9 \%)$ \\
\hline Smoking & $4(4.8 \%)$ \\
\hline Khat chewing & $33(39.8 \%)$ \\
\hline Child-Pugh score & \\
\hline Child class A(n) & 0 \\
\hline Child class B(n) & $39(47 \%)$ \\
\hline Weight(kg) & $58.6 \pm 9$ \\
\hline Hip circumference $(\mathrm{cm})$ & $96.7 \pm 88.8$ \\
\hline West circumference(cm) & $9.75 \pm 2.94$ \\
\hline Systolic blood pressure $(\mathrm{mm} \mathrm{Hg})$ & $120.02 \pm 16.5$ \\
\hline Diastolic blood pressure $(\mathrm{mm} \mathrm{Hg})$ & $78.5 \pm 12.2$ \\
\hline BMl(K/M $\left.{ }^{2}\right)$ & $21.94 \pm 3.7$ \\
\hline Waist to hip ratio & $0.94 \pm 0.32$ \\
\hline Glucose (mg/dl) & $89.8 \pm 25.5$ \\
\hline HDL cholesterol (mg/dl) & $62.04 \pm 24.34$ \\
\hline LDL cholesterol & $76.8 \pm 48.07$ \\
\hline Triglyceride $(\mathrm{mg} / \mathrm{dl})$ & $188.07 \pm 84.45$ \\
\hline Total cholesterol $(\mathrm{mg} / \mathrm{dl})$ & $210.5 \pm 57.10$ \\
\hline Total protein(g/dl) & \\
\hline
\end{tabular}

(Continued) 
Table I (Continued).

\begin{tabular}{|l|l|}
\hline Variables & Mean and Standard Deviation (Frequency) \\
\hline Albumin $(\mathrm{g} / \mathrm{dl})$ & $4.2 \pm 1.01$ \\
\hline Bilirubin $(\mathrm{mg} / \mathrm{dl})$ & $0.7 \pm 0.6$ \\
\hline Hgb $(\mathrm{g} / \mathrm{dl})$ & $9.75 \pm 2.94$ \\
\hline Serum k (mmol/l) & $3.8 \pm 0.07$ \\
\hline Serum Na (mmol/l) & $140 \pm 1.6$ \\
\hline Serum cl (mmol/l) & $105 \pm 0.3$ \\
\hline Serum iCa (mmol/l) & $1.2 \pm 0.3$ \\
\hline Serum TCA (mmol/l) & $2.13 \pm 0.3$ \\
\hline PH & $7.8 \pm 0.11$ \\
\hline Prothrombin time (second) & $2.08 \pm 0.8$ \\
\hline INR & $2.08 \pm 0.8$ \\
\hline
\end{tabular}

$31(39.8 \%)$, hepatitis steatosis $1(1.2 \%)$, autoimmune hepatitis $1(1.2 \%)$ and alcoholic liver disease $12(16.9 \%)$, adult bile dectopenea 3(3.6\%), medications 1 (1.2\%) (Table 2). The complications of liver disease were ascites 72 (86.7\%), hepatic encephalopathy 2(2.4\%), muscle crump 6(7.2\%), and visceral hemorrhage $9(10.8 \%)$ (Table 3). Table 4 shows abnormalities of ECG components with their relation to the disease severity. Twenty-eight (50.9\%) of cirrhotic patients had sinus tachycardia, 1(1.8\%) of the patients had sinus bradycardia, $8(14.5 \%)$ of the patients had left bundle branch block, left axis deviation was 22 (40\%), left ventricular hypertrophy was 16(29.1\%), P wave abnormality was 46(83.6\%), wider QRs was 26(47.3\%), QT prolongation was 52 (94.5\%), QTc prolongation was $49(89.1 \%)$, bradycardia was 5(9.1\%), Prolonged T duration was 54 (98.2\%), Prolonged PR interval was 15 (27.3\%) (Table 4, Figure 1). Among the patients with prolonged QT interval, 24 (61.5\%) were in child class B and 28 (63.6\%) were in child class C (Figure 2). Among the patients with prolonged QTc interval, 6(15.4\%) were child class B and 43 (97.7\%) were in child class C (Table 5).

\section{Discussion}

Even if some have common alterations at the molecular level, the underlying mechanism of electrophysiological abnormalities in CLD patients is not known. ${ }^{17}$ Sympathetic nervous activity influences the heart rate and electromechanical coupling by several mechanisms. Several receptors and post-receptor defects have been described in cirrhosis with

Table 2 Etiologies of CLD Patients with Severity of the Disease

\begin{tabular}{|l|l|l|l|}
\hline \multirow{2}{*}{ Etiologies of CLD } & Total Numbers & \multicolumn{2}{l|}{ The Severity of the Disease } \\
\cline { 3 - 4 } & & Child Class B(39) & \multicolumn{1}{l|}{ Child Class C(44) } \\
\hline HVB & $34(41 \%)$ & $16(41 \%)$ & $18(40.9 \%)$ \\
HVC & $3 I(39.8 \%)$ & $13(33.3 \%)$ & $18(40.9 \%)$ \\
Hepatic steatosis & $\mathrm{I}(\mathrm{I} .2 \%)$ & 0 & $\mathrm{I}(2.3 \%)$ \\
Autoimmune hepatitis & $\mathrm{I}(\mathrm{I} .2 \%)$ & 0 & $\mathrm{I}(2.3 \%)$ \\
Alcoholic liver disease & $\mathrm{I}(\mathrm{I} \% .9 \%)$ & $9(23.1 \%)$ & $3(6.8 \%)$ \\
Adult bile dectopenea & $3(3.6 \%)$ & $\mathrm{I}(2.6 \%)$ & $2(4.5 \%)$ \\
Medications & $\mathrm{I}(\mathrm{I} .2 \%)$ & 0 & $\mathrm{I}(2.3 \%)$ \\
\hline
\end{tabular}


Table 3 Complications of CLD Patients with Severity of the Disease

\begin{tabular}{|l|l|l|l|}
\hline A Complication of Liver Diseases & \multirow{2}{*}{ Total Numbers } & \multicolumn{2}{|c|}{ The Severity of Liver Disease } \\
\cline { 3 - 4 } & & Child Class B(39) & Child Class C(44) \\
\hline Visceral hemorrhage & $9(10.8 \%)$ & $4(10.3 \%)$ & $5(11.4 \%)$ \\
Ascites & $72(86.7 \%)$ & $35(89.7 \%)$ & $37(84.1 \%)$ \\
Hepatic encephalopathy & $2(2.4 \%)$ & 0 & $2(4.5 \%)$ \\
Muscle cramp & $6(7.2 \%)$ & $1(2.6 \%)$ & $5(11.4 \%)$ \\
\hline
\end{tabular}

Table 4 ECG Abnormalities with Their Correlation to the Severity of Liver Diseases

\begin{tabular}{|c|c|c|c|c|c|c|}
\hline \multirow[t]{3}{*}{ S.NO } & \multirow[t]{2}{*}{ ECG Abnormalities } & \multicolumn{2}{|c|}{ The Severity of the Disease } & \multirow[b]{2}{*}{ Total (83) } & \multirow[b]{2}{*}{$\mathbf{P}$} & \multirow[b]{2}{*}{$\begin{array}{l}\text { Chi- } \\
\text { Square }\end{array}$} \\
\hline & & $\begin{array}{l}\text { Child Class } \\
\text { B (39) }\end{array}$ & $\begin{array}{l}\text { Child Class } \\
\text { C (44) }\end{array}$ & & & \\
\hline & $\begin{array}{l}\text { ECG Abnormality (at Least One of the } \\
\text { Following) }\end{array}$ & $29(74.4 \%)$ & $26(59.1 \%)$ & $55(66.3 \%)$ & 0.142 & 2.156 \\
\hline I. & Sinus tachycardia & 14 (35.9\%) & 14 (31.8\%) & $28(33.7 \%)$ & 0.45 & 2.796 \\
\hline 2. & Sinus bradycardia & I (2.6\%) & $0 \%$ & I (0.12\%) & 0.45 & 2.796 \\
\hline 3. & Left bundle branch block & $2(5.1 \%)$ & $6(13.6 \%)$ & $8(9.6 \%)$ & 0.45 & 2.796 \\
\hline 4. & Left axis deviation & $13(33.3 \%)$ & 9 (20.5\%) & $22(26.5 \%)$ & 0.185 & 1.76 \\
\hline 5. & Left ventricular hypertrophy & II (28.2\%) & $5(11.4 \%)$ & $16(19.28 \%)$ & 0.052 & 3.768 \\
\hline 6. & P wave abnormality & $9(23.1 \%)$ & 37 (84.1\%) & 46 (55.4\%) & 0.69 & 0.159 \\
\hline 7. & Wider QRs duration & $9(23.1 \%)$ & $17(38.6 \%)$ & 26 (31.3\%) & 0.127 & 2.327 \\
\hline 8. & QT prolongation & $24(61.5 \%)$ & $28(63.6 \%)$ & $52(62.7 \%)$ & 0.844 & 1.718 \\
\hline 9. & QTc prolongation & $6(15.4 \%)$ & $43(97.7 \%)$ & 49 (59.03\%) & 0.023 & 0.039 \\
\hline 10. & Bradycardia & $4(10.3 \%)$ & I (2.3\%) & $5(6.02 \%)$ & 0.182 & 2.328 \\
\hline 11. & Prolonged $\mathrm{T}$ duration & II (28.2\%) & $43(97.7 \%)$ & 54 (65.06\%) & 1.00 & 0.897 \\
\hline 12. & PR interval prolongation & $10(25.6 \%)$ & 5 (II.4\%) & 15 (I8.07\%) & 0.092 & 2.846 \\
\hline
\end{tabular}

reduced B-receptor density and sensitivity, altered G protein, and calcium channel dysfunctions. All these mechanisms are responsible for electrophysiological abnormalities. ${ }^{21}$

\section{QT Prolongation}

Fifty-two (62.7\%) of the patients had QT interval prolongation. This finding is in line with the previous studies. ${ }^{35-37}$

\section{Associated Factors of QT Interval Prolongation}

The independent factors significantly associated with QT interval prolongation, by logistic regression, in this study were systolic hypotension $(p=0.003)$ and overweight $(p=0.018)$. This study is not in line with the previous studies. ${ }^{7,35,36}$ In this study, there was a significant association $(\mathrm{p}=0.003)$ between systolic hypotension and QT interval prolongation. The possible explanation will be in liver diseases the circulation is hyperkinetic with increased cardiac output and plasma volume and decreased systemic vascular resistance and arterial blood pressure. ${ }^{22}$ According to the "peripheral artery vasodilation hypothesis", systemic vasodilation leads to arterial underfilling and activation of compensatory vasoactive and homeostatic mechanisms. ${ }^{23}$ Thus, the sympathetic nervous system (SNS), renin-angiotensin-aldosterone system 


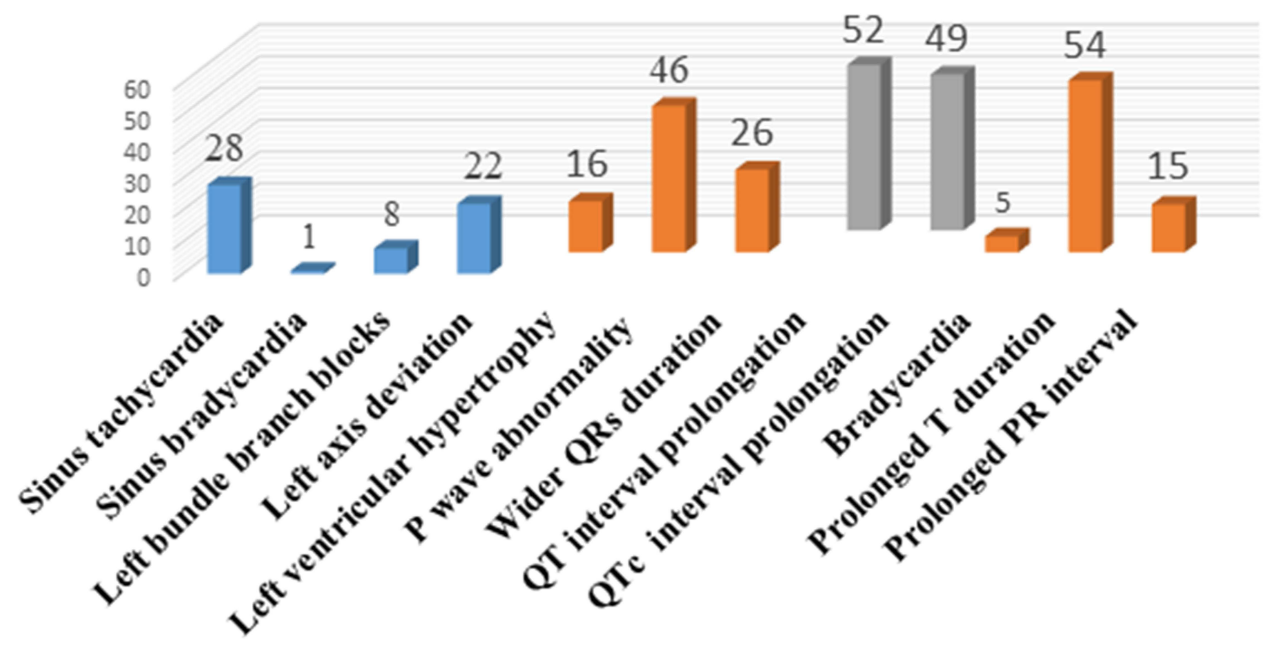

Figure I Particular types of ECG abnormality.

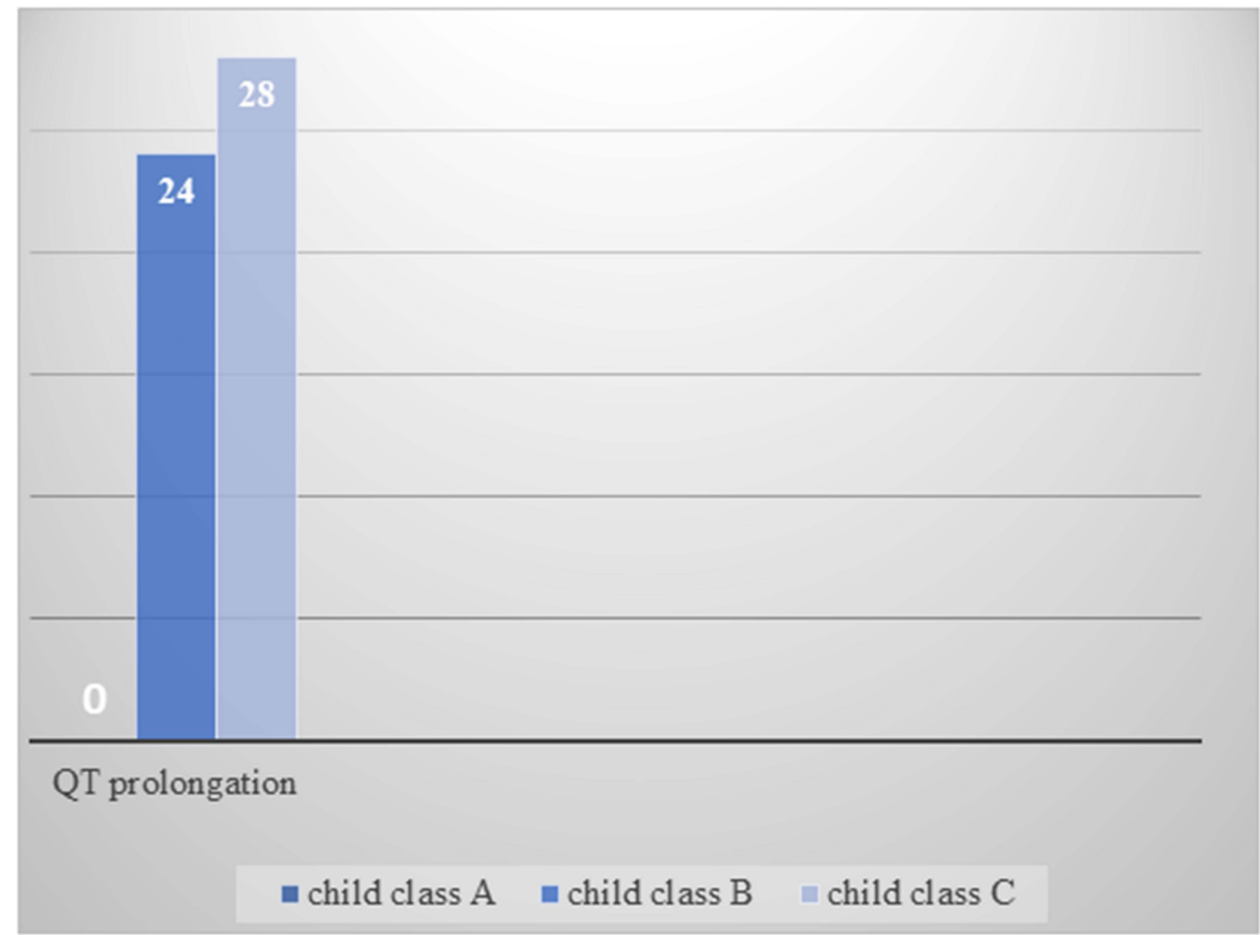

Figure 2 QT prolongation in each child classes.

(RAAS), neuro pituitary release of vasopressin, and endothelin system (ETS) are activated. ${ }^{24-26}$ Beta-adrenergic receptor signaling is impaired because of sympathetic over-activity and prolonged exposure to noradrenaline. ${ }^{2}$ Low arterial blood pressure and reduced central blood volume are the main triggers of SNS via baroreceptor and volume-mediated receptor, respectively. ${ }^{27}$ Sympathetic hyperactivity causes direct myocyte damage and reduced $\beta$-adrenergic function. Desensitization of $\beta$-adrenergic receptor leads to decreased cAMP production in myocytes which intern decrease activation of phosphorylating enzyme protein kinase which intern causes QT interval prolongation. ${ }^{28}$

This study also shows a significant association $(p=0.018)$ between Overweight and QT interval prolongation. Being overweight affects the cardiac conduction system. There is also a significant increase in the incidence of arrhythmias in 
Table 5 QT and QTc Interval Prolongation with Their Correlation to the Severity of the Disease

\begin{tabular}{|l|l|l|l|l|l|l|}
\hline \multirow{2}{*}{ S. No } & \multirow{2}{*}{ QT Prolongation } & \multicolumn{2}{|l|}{ The Severity of the Disease } & \multicolumn{4}{|l|}{} \\
\cline { 3 - 7 } & & Child Class B (39) & Child Class C (44) & Total(83) & P & Chi-Square \\
\hline I. & QT prolongation & $24(61.5 \%)$ & $28(63.6 \%)$ & $52(62.7 \%)$ & 0.844 & 1.718 \\
2. & QTc prolongation & $6(15.4 \%)$ & $43(97.7 \%)$ & $49(59.03 \%)$ & 0.023 & 0.039 \\
\hline
\end{tabular}

obese persons. Being overweight is linked to the cardiac autonomic nervous system. An increased plasma catecholamine level in obesity elevates free fatty acid (FFA) levels, which affects cardiac repolarization. ${ }^{29}$ High glucose concentrations in obesity decrease nitric oxide (NO) availability. ${ }^{30}$ The anatomical cardiac changes in obesity result in physiological alterations in cardiac myocytes. ${ }^{31}$ There is a higher risk of developing new-onset atrial fibrillation (AF) independent of other CVD risk factors with each unit increase in BMI. ${ }^{32,33}$ Changes in the sinus node, atrioventricular node, and right bundle branch may also lead to cardiac conduction abnormalities. These changes occur when cardiomyocytes slowly accumulate fat between cardiac muscle fibers. Abnormalities in cardiac conduction and arrhythmias increase the risk of developing $\mathrm{HF}^{29} \mathrm{AF}$, for instance, may result in $\mathrm{HF}$ by causing tachycardia-induced cardiomyopathy through multiple mechanisms, such as uncontrolled heart rate, loss of atrioventricular synchrony, irregularity in the ventricular rhythm, valvular regurgitation, and neurohormonal effects. These mechanisms generally will cause QT interval prolongation. ${ }^{34}$

\section{Association of QT Interval with the Severity of Liver Disease}

The most frequently studied ECG abnormality in liver diseases is QT interval prolongation. Most studies show that QT interval prolongation is associated with the severity of liver disease. This study shows that there was an association $(\mathrm{p}=$ 0.023) between QTc interval prolongation and the severity of liver disease. This finding is in line with the previous studies. ${ }^{7,35-37}$ But this study was not in line with the study conducted at the medical university of Warsaw, Poland. ${ }^{38}$

\section{Limitations of the Study}

The study design of this study was cross-sectional. So that it will be difficult to see the exact effects of independent variables on an outcome. The other limitation was less sample size of the study since it was 83 .

\section{Conclusion}

The total number of patients with QT prolongation was 52 (62.7\%). In this study, it has been concluded that QT and corrected QT interval prolongation were increased when the severity of the disease is more advanced like in child class C. QTc interval prolongation is correlated with the severity of the diseases. Moreover, this study showed that the risk factors (systolic hypotension and overweight) in logistic regression were significantly associated with QT interval prolongation.

\section{Abbreviations}

AF, atrial fibrillation; ALD, alcoholic liver disease; ALP, alkaline phosphatase; ALT, alanine aminotransferase; AST, aspartate amino transferase; BMI, body mass index; BP, blood pressure; cAMP, cyclic adenosine monophosphate; CHF, congestive heart failure; CKD, chronic kidney disease; CLD, Chronic liver diseases; CO, cardiac output; CTP, childturcotte-pugh; CVD, cardiovascular disease; ECG, electrocardiogram; ETS, endothelin system; FFA, free fatty acids; HBV, hepatitis B virus; HCV, hepatitis C virus; HDL, high-density lipoprotein; HF, heart failure; HGB, hemoglobin; Ica, ionized calcium; INR, International normalized ratio; IRB, institutional review board; ISI, an international sensitivity index; LBBB, left bundle branchblock; LDL, low-density lipoprotein; LV, left ventricles; MNPT, mean normal prothrombin time; NAFLD, nonalcoholic fatty liver disease; NO, nitric oxide; QTc, correctedQT; RAAS, renin angiotensin aldosterone system; SNS, sympathetic nervous system; TCA, total calcium; TG, triglyceride; VLDL, very-low-density lipoprotein; WHO, World Health Organization. 


\section{Ethics}

The study was conducted following the declaration of Helsinki.

\section{Acknowledgments}

I thank Jimma University for funding me to conduct this research and for general support. I would like to proffer my deepest gratitude to my colleague, Banjaw Zelalem for his assistance during manuscript writing.

\section{Disclosure}

The authors report no conflicts of interest for this work.

\section{References}

1. GBD Mortality and Causes of Death Collaborators. Global, regional, and national life expectancy, all-cause mortality, and cause-specific mortality for 249 causes of death, 1980-2015, a systematic analysis for the Global Burden of Disease Study 2015. Lancet. 2016;388:1459-1544. doi:10.1016/ S0140-6736(16)31012-1

2. Møller S, Henriksen JH. Cirrhotic cardiomyopathy, a pathophysiological review of circulatory dysfunction in liver disease. Heart. 2002;87(1):9-15. doi:10.1136/heart.87.1.9

3. Zambruni A, Di Micoli A, Lubisco A, Domenicali M, Trevisani F, Bernardi M. QT interval correction in patients with cirrhosis. $J$ Cardiovasc Electrophysiol. 2007;18:77-82. doi:10.1111/j.1540-8167.2006.00622.x

4. Ward CA, Ma Z, Lee SS, Giles WR. Potassium currents in atrial and ventricular myocytes from a rat model of cirrhosis. Am J Physiol. 1997;273:537-544.

5. Kempler P, Váradi A, Szalay F. Autonomic neuropathy and prolongation of QT-interval in liver disease. Lancet. 1992;340:318. doi:10.1016/01406736(92)92417-E

6. Karagiannakis DS, Papatheodoridis G, Vlachogiannakos J. Recent advances in cirrhotic cardiomyopathy. Dig Dis Sci. 2015;60:1141-1151.

7. Genovesi S, Prata Pizzala DM, Pozzi M, et al. QT interval prolongation and decreased heart rate variability in cirrhotic patients, relevance of hepatic venous pressure gradient and serum calcium. Clin Sci. 2009;116:851-859. doi:10.1042/CS20080325

8. Valeriano V, Funaro S, Lionetti R, et al. Modification of cardiac function in cirrhotic patients with and without ascites. Am J Gastroenterol. 2000;95 (11):3200-3205. doi:10.1111/j.1572-0241.2000.03252.x

9. Ates F, Topal E, Kosar F, et al. The relationship of heart rate variability with severity and prognosis of cirrhosis. Dig Dis Sci. 2006;51 (9):1614-1618. doi:10.1007/s10620-006-9073-9

10. Hendrickse MT, Thuluvath PJ, Trigger DR. Natural history of autonomic neuropathy in chronic liver disease. Lancet. 1992;339(8807):1462-1464. doi:10.1016/0140-6736(92)92042-E

11. Milan A, Caserta MA, Del Colle S, et al. Baroreflex sensitivity correlates with left ventricular morphology and diastolic function in essential hypertension. J Hypertens. 2007;25(8):1655-1664. doi:10.1097/HJH.0b013e3281ddb0a0

12. Lantelme P, Khattab F, Custard MA, et al. Spontaneous baroreflex sensitivity, toward an ideal index of cardiovascular risk in hypertension? J Hypertens. 2002;20(5):935-944. doi:10.1097/00004872-200205000-00029

13. Okada N, Takahashi N, Yufu K, et al. Baroreflex sensitivity predicts cardiovascular events in patients with type 2 diabetes mellitus without structural heart disease. Circ J. 2010;74(7):1379-1383. doi:10.1253/circj.CJ-09-0960

14. Yufu K, Takahashi N, Okada N, et al. Gender difference in baroreflex sensitivity to predict cardiac and cerebrovascular events in type 2 diabetic patients. Circ J. 2011;75(6):1418-1423. doi:10.1253/circj.CJ-10-1122

15. Mircoli L, Rivera R, Bonforte G, et al. Influence of left ventricular mass, uremia and hypertension on vagal tachycardic reserve. $J$ Hypertens. 2003;21(8):1547-1553. doi:10.1097/00004872-200308000-00020

16. Braverman AC, Steiner MA, Picus D, White H. High-output congestive heart failure following transjugular intrahepatic portal-systemic shunting. Chest. 1995;107(5):1467-1469.11. doi:10.1378/chest.107.5.1467

17. Møller S, Henriksen JH. Cardiovascular complications of cirrhosis. Gut. 2008;57(2):268-278. doi:10.1136/gut.2006.112177

18. Pugh RN, Murray-Lyon IM, Dawson JL, et al. Transection of the esophagus for bleeding oesophagealvarices. Br J Surg. 1973;60:646. doi:10.1002/ bjs. 1800600817

19. Harmer AR, Valentin JP, Pollard CE. On the relationship between a block of the cardiac $\mathrm{Na}^{+}$channel and drug-induced prolongation of the QT interval. Br J Pharmacol. 2011;164(2):260-273. doi:10.1111/j.1476-5381.2011.01415.x

20. Debbie H. Basic ECG recording and interpretation. 12 Lead Electrocardiogram Module 1; 2012:1-31.

21. Zambruni A, Trevisani F, Caraceni P, Bernardi M. Cardiac electrophysiological abnormalities in patients with cirrhosis. $J$ Hepatol. 2006;44 (5):994-1002. doi:10.1016/j.jhep.2005.10.034

22. Groszmann RJ. Hyperdynamic circulation of liver disease 40 years later: pathophysiology and clinical consequences. Hepatology. 1994;20:1359-1363. doi:10.1002/hep.1840200538

23. Schrier RW, Arroyo V, Bernardi M, et al. Peripheral arterial vasodilation hypothesis: a proposal for the initiation of renal sodium and water retention in cirrhosis. Hepatology. 1988;5:1151-1157.

24. Henriksen JH, Møller S, Ring-Larsen H, et al. The sympathetic nervous system in liver disease. J Hepatol. 1998;29:328-341. doi:10.1016/S01688278(98)80022-6

25. Bernardi M, Trevisani F, Gasbarrini A, et al. Hepatorenal disorders. Role of the renin-angiotensin-aldosterone system. Semin Liver Dis. 1994;14:23-34. doi:10.1055/s-2007-1007295

26. Møller S, Henriksen JH. Endothelins in chronic liver disease. Scand J Clin Lab Invest. 1996;56:481-490. doi:10.3109/00365519609088803 
27. Brum PC, Kosek J, Patterson A, Bernstein D, Kobilka B. Abnormal cardiac function associated with sympathetic nervous system hyperactivity in mice. Am J Physiol Heart Circ Physiol. 2002;283:1838-1845. doi:10.1152/ajpheart.01063.2001

28. Lee SS, Marty J, Mantz J, Samain E, Braillon A, Lebrec D. Desensitization of myocardial $\beta$-adrenergic receptors in cirrhotic rats. Hepatology. 1990;12:481-485. doi:10.1002/hep.1840120306

29. Poirier P, Giles TD, Bray GA, et al.; American Heart Association. Obesity committee of the council on nutrition, physical activity, and metabolism obesity and cardiovascular disease, pathophysiology, evaluation, and effect of weight loss, an update of the 1997 American Heart Association Scientific Statement on obesity and heart disease from the obesity committee of the council on nutrition, physical activity, and metabolism. Circulation. 2006;113(6):898-918. doi:10.1161/CIRCULATIONAHA.106.171016

30. Gradman AH, Alfayoumi F. From left ventricular hypertrophy to congestive heart failure, management of hypertensive heart disease. Prog Cardiovasc Dis. 2006;48(5):326-341. doi:10.1016/j.pcad.2006.02.001

31. Schoonderwoerd BA, Smit MD, Pen L, Van Gelder IC. New risk factors for atrial fibrillation, causes of 'not-so-lone atrial fibrillation'. Europace. 2008;10(6):668-673. doi:10.1093/europace/eun124

32. Asghar O, Alam U, Hayat SA, Aghamohammadzadeh R, Heagerty AM, A Malik R. Obesity, diabetes, and atrial fibrillation; epidemiology, mechanisms, and interventions. Curr Cardiol Rev. 2012;8(4):253-264. doi:10.2174/157340312803760749

33. Piot O. Atrial fibrillation and heart failure, a dangerous criminal conspiracy. Annales de Cardiologie Et d'Angeiologie. $2009 ; 58($ Suppl 1):S14-S16. doi:10.1016/S0003-3928(09)73391-8

34. Scardi S, Mazzone C. [Atrial fibrillation and heart failure, cause or effect?] Ital Heart J Suppl. 2002;3(9):899-907. Italian.

35. Puthumana L, Chaudhry V, Thuluvath PJ. Prolonged QTc interval and its relationship to autonomic cardiovascular reflexes in patients with cirrhosis. J Hepatol. 2001;35(6):733-738. doi:10.1016/S0168-8278(01)00217-3

36. Bernardi M, Calandra S, Colantoni A, et al. Q-T interval prolongation in cirrhosis, Prevalence, relationship with severity, and etiology of the disease and possible pathogenetic factors. Hepatology. 1998;27:28-34. doi:10.1002/hep.510270106

37. Mohamed R, Forsey PR, Davies MK, Neuberger JM. Effect of liver transplantation on QT interval prolongation and autonomic dysfunction in end-stage liver disease. Hepatology. 1996;23(5):1128-1134. doi:10.1002/hep.510230529

38. Główczyńska R, Galas M, Ołdakowska-Jedynak U, et al. QT interval, the relationship with severity and etiology of liver disease and prognostic value after liver transplantation. Ann Transplant. 2018;23:622-630. doi:10.12659/AOT.908769

Research Reports in Clinical Cardiology is an international, peer-reviewed, open access journal publishing original research, reports, editorials, reviews and commentaries on all areas of cardiology in the clinic and laboratory. The manuscript management system is completely online and includes a very quick and fair peer-review system. Visit http://www.dovepress.com/testimonials.php to read real quotes from published authors.

Submit your manuscript here: http://www.dovepress.com/research-reports-in-clinical-cardiology-journal 